\title{
GEOPROCESSAMENTO DAS NOTIFICAÇÕES DE LEPTOSPIROSE HUMANA ASSOCIADAS AOS FATORES DE RISCO: PRESENÇA DE ESGOTO A CÉU ABERTO, BACIAS HIDROGRÁFICAS E LIXO PERIDOMICILIAR NO ESTADO DE SANTA CATARINA EM 2010
}

\author{
GEOPROCESSING OF HUMAN LEPTOSPIROSIS NOTIFICATION ASSOCIATED \\ TO RISK FACTORS: SEWAGE AT HEAVEN OPEN, BASIN RIVER AND \\ PERIDOMICILIARY WASTE IN SANTA CATARINA STATE IN 2010
}

C. R. BASTOS*1, R. M. SANTOS ${ }^{2}$, L. A. MATHIAS ${ }^{3}$, A. S. FERRAUDO ${ }^{4}$.

\begin{abstract}
RESUMO
O objetivo deste trabalho foi analisar a distribuição espacial da leptospirose humana no Estado de Santa Catarina, no ano de 2010, em relação a sexo, idade, região e aos fatores considerados de risco pelo Ministério da Saúde: bacias hídricas, esgoto a céu aberto e lixo peridomiciliar. Os dados referentes ao número e às características das notificações foram retirados do Sistema de Informação de Agravos de Notificação - Sinan; já os dados de território, população e estrutura de moradia, da base de dados do Instituto Brasileiro de Geografia e Estatística - IBGE, e as informações referentes às bacias hidrográficas, da Agência Nacional de Águas - ANA. Para realizar o geoprocessamento e georreferenciamento dos dados, foi utilizado o software TerraView. No ano de 2010, foram notificados 407 casos de leptospirose em todo o Estado, principalmente no litoral, com a maior concentração de casos na região Nordeste e a menor no Centro-Oeste catarinense. Dos 407 casos notificados, 344 (84,5\%) ocorreram em pessoas do sexo masculino e $63(15,5 \%)$ do sexo feminino; $65 \%$ dos casos foram em pessoas na faixa etária de 20 a 39 anos. Em relação aos fatores de risco, o município de Joinvile é o que apresenta maior número de esgotos a céu aberto, sendo também o município com maior número de notificações. O litoral catarinense concentra a maioria das notificações e é a macrorregião com maior presença de lixo. Em relação às bacias hidrográficas, os rios Cubatão, Tijucas, Das Antas e Itajaí-Açu, os mais caudalosos e explorados do Estado, abastecem as cidades mais acometidas pela leptospirose. Com as informações geradas após o geoprocessamento dos dados, pôde-se observar a associação entre infecção humana por Leptospira spp. e os fatores de risco: presença de esgoto a céu aberto, bacias hidrográficas e lixo acumulado no Estado de Santa Catarina em 2010.
\end{abstract}

PALAVRAS-CHAVE: ZOONOSES. Leptospira spp. SAÚDE PÚBLICA.

ÁREA TEMÁTICA: Saúde Pública 